\title{
A NOÇÃO DE ENUNCIADO REITOR DE MICHEL FOUCAULT E A ANÁLISE DE OBJETOS DISCURSIVOS MIDIÁTICOS*
}

\author{
Jefferson Voss** \\ Pedro Navarro***
}

\begin{abstract}
Resumo: Este texto tem como escopo discorrer sobre a noção de enunciado reitor, erigida no interior do método arqueológico de Michel Foucault, e discutir sua operacionalidade para a Análise de Discurso (AD). Para tanto, arguimos, primeiramente, sobre as possibilidades de trabalho com o método arqueológico. Na sequência, apresentamos algumas ressalvas que precisariam ser feitas diante da especificidade de algumas materialidades discursivas contemporâneas. Essas ressalvas dizem respeito a algumas noções arqueológicas de Foucault: formação discursiva, enunciado reitor, árvore de derivação enunciativa etc. Finalmente, exploramos a noção de enunciado reitor de Foucault e sua relação com a constituição do corpus de uma pesquisa. Na tentativa de mostrar a operacionalidade de tal noção, analisaremos o papel de enunciado reitor desempenhado pelo slogan do Governo do exPresidente Luís Inácio Lula da Silva na gestão presidencial de 2002 a 2006, "Brasil: um país de todos".
\end{abstract}

Palavras-chave: Michel Foucault. Enunciado reitor. Método arqueológico. Análise do Discurso.

* Este trabalho resulta de uma discussão proveniente da dissertação de mestrado "O Conceito de Formação Discursiva de Foucault e o Tratamento de Objetos da Mídia: sobre a responsabilidade social na publicidade impressa brasileira", defendida por Jefferson Voss em março de 2011 (Apoio: CNPq, Processo: 131032/2010-0).

** IEL/UNICAMP, doutorando. Mestre em Letras em Estudos Linguísticos pela Universidade Estadual de Maringá. Email: jeffersonvoss@yahoo.com.br.

*** Universidade Estadual de Maringá, Professor Associado. Doutor em Linguística e Língua Portuguesa pela UNESP - Araraquara. Email: plnavarro@uol.com.br. 


\section{INTRODUÇÃO}

As discussões que apresentamos neste texto, a partir da noção de “enunciado reitor", desenvolvido por Michel Foucault (2008), e tomando como mote o slogan do Governo do ex-presidente Luís Inácio Lula da Silva (2002 a 2006), "Brasil: um país de todos", são motivadas por algo que é fundamental nos estudos discursivos de orientação foucaultiana: a compreensão do modo como os saberes se constituem e formam redes de discursos. Em outros termos, trata-se de analisar o feixe de relações que permite localizar e descrever determinadas regras de formação discursiva, em meio à dispersão enunciativa que lhe é característica. Sobretudo quando a análise abarca textos midiáticos, essa dispersão se destaca ainda mais, dadas as características dessa produção discursiva.

No caso que diretamente nos interessa, o movimento de descrição dos saberes que atravessam e constituem o discurso midiático destina-se tanto à busca de uma regularidade na dispersão do referido slogan, considerando-se, de saída, seu caráter de acontecimento, quanto à análise de sua recorrência enunciativa. Como ensina Foucault, a regularidade designa, na análise arqueológica, "o conjunto das condições nas quais se exerce a função enunciativa" (2008, p. 163) que assegura e define a existência dos enunciados.

Assim, em "Brasil: um país de todos", os enunciados que esse slogan rege e com os quais forma um campo associativo indicam o exercício de uma prática discursiva na qual a ideia de igualdade de oportunidades é reinterpretada, parafraseada e recolada na ordem dos discursos. Nossa análise parte, então, da consideração de que todo enunciado abarca um campo de elementos enunciativos que o antecede, o que sinaliza o funcionamento da memória e do esquecimento na retomada, redistribuição, reorganização e deslocamento de um passado enunciativo, em que oferecer oportunidades de trabalho, saúde, alimentação, educação e lazer para todos já vinha se constituindo como parte de um dispositivo de poder, tanto político quanto econômico, que visa ao governo dos vivos. 


\section{ACONTECIMENTO, ENUNCIADO E SÉRIE ENUNCIATIVA}

$\mathrm{Na}$ empreitada arqueológica, há três noções bastante relevantes na constituição de um lugar de entremeio para a organização de um corpus: acontecimento discursivo, enunciado e série enunciativa. Em resumo, o método arqueológico trata de verificar o estatuto de acontecimento discursivo que o enunciado desempenha no arquivo (conjuntos de todos os enunciados existentes). Os movimentos da história se desenham pelas séries de enunciados postos lado a lado e representando, cada um deles, um acontecimento discursivo.

Podemos entender, a partir de Foucault (2008), que o enunciado é uma unidade que, em parte dos trabalhos que antecedem $A$ arqueologia do saber (Histoire de la folie à l'âge classique [1961], Naissance de la clinique [1963], Les mots e les choses: une archéologie des sciences humaines [1966]), foi tratada a partir da descrição do desempenho de sua função de existência. Essa função percorreu desde as relações do enunciado com seu referencial e com as modalidades enunciativas que nele operam até a identificação do domínio de outros enunciados em que se insere e a análise do estatuto de sua materialidade como signo de sua existência. Esquematicamente, foram, então, quatro os traços que puderam definir a existência de um enunciado: seu referencial, seu sujeito (modalidades enunciativas), seu domínio associado e sua materialidade.

Foucault, no método arqueológico, está interessado no enunciado como acontecimento discursivo: índice paradoxal de novidade e de repetição, na história. $\mathrm{O}$ acontecimento discursivo tem a ver com o estatuto que Foucault dá à regularidade do enunciado em sua relação com o arquivo. Para ele, é necessário que se reconheça a singularidade de cada enunciado como um acontecimento discursivo:

[...] um enunciado é sempre um acontecimento que nem a língua nem o sentido podem esgotar inteiramente. Trata-se de um acontecimento estranho, por certo: inicialmente porque está ligado, de um lado, a um gesto de escrita ou à articulação de uma palavra, mas por outro, abre para si mesmo uma existência remanescente no campo da memória, ou na materialidade dos manuscritos, dos livros 
e de qualquer forma de registro; em seguida, porque é único como todo acontecimento, mas está aberto à repetição, à transformação, à reativação; finalmente, porque está ligado não apenas a situações que o provocam, e a consequências por ele ocasionadas, mas, ao mesmo tempo, e segundo uma modalidade inteiramente diferente, a enunciados que o precedem e o seguem. (FOUCAULT, 2008, p. 31$32)$.

Daí depreendemos algumas das características do desempenho da função enunciativa em relação ao acontecimento: (1) o enunciado se torna acontecimento pela sua materialização, a materialidade é índice da função de acontecimento do enunciado; (2) o enunciado é acontecimento porque é algo que instaura memória; depois, (3) o enunciado, ao mesmo tempo em que é único, pode ser reutilizado e reaparecer em outras enunciações; e, por fim, (4) o enunciado está vinculado a uma cadeia enunciativa ou a um domínio de coexistência, em que mantém relação dispersa com outros enunciados, anteriores e ulteriores.

Foucault insiste em destacar a propriedade de unicidade do enunciado, bem como a sua regularidade (em oposição à originalidade): não é porque o enunciado é acontecimento único que deve ser necessariamente interpretado como original, no sentido de que fundaria memória. $\mathrm{O}$ enunciado é único, mas regular, de modo que pode transformar a memória - desde que esteja sempre apoiado nela.

Corre-se o risco, contudo, de se passar a descrever um grande sistema de relações homogêneas quando da descrição dos acontecimentos instaurados pelo desempenho da função enunciativa. Esse tipo de estabelecimento de relações analógicas e de causalidade entre os acontecimentos é uma prática do tipo de história que Foucault chama de global e a que é por ele criticada. Segundo discute Foucault, nesse tipo de história global,

[...] supõe-se que entre todos os acontecimentos de uma área espaçotemporal bem definida, entre todos os fenômenos cujo rastro foi encontrado, será possível estabelecer um sistema de relações homogêneas: rede de causalidade permitindo derivar cada um deles relações de analogia mostrando como eles se simbolizam uns aos outros, ou como todos exprimem um único e mesmo núcleo central (2008, p. 11). 
A análise arqueológica, baseada na nova história (a história geral), mantém outra relação com o tratamento dos acontecimentos discursivos. Questionando esse lugar de uma história global, uma história geral “[...] problematiza as séries, os recortes, os limites, os desníveis, as defasagens, as especificidades cronológicas, as formas singulares de permanência, os tipos possíveis de relação" (FOUCAULT, 2008, p. 11). Toda a continuidade em torno da qual se engendram as formas tradicionais da história é questionada pela história geral.

Nessa discussão em torno das diferenças entre a história geral e a história global (cf. a Introdução de $A$ arqueologia do saber), aparece ainda uma reflexão sobre o que Foucault entende por séries de enunciados:

Mas não que ela [a história geral] procure obter uma pluralidade de histórias justapostas e independentes umas das outras [...]. O problema que se apresenta - e que define a tarefa de uma história geral - é de determinar que forma de relação pode ser legitimamente descrita entre essas diferentes séries; que sistema vertical podem formar; qual é, de umas às outras, o jogo das correlações e das dominâncias; de que efeito podem ser as defasagens, as temporalidades diferentes, as diversas permanências; em que conjuntos distintos certos elementos podem figurar simultaneamente; em resumo, não somente que séries, mas que "séries de séries" - ou, em outros termos, que "quadros" - é possível constituir. (2008b, p. 11).

Interpretando via um lugar cinematográfico pouco definido, podemos lembrar que a imagem efêmera é nada mais que uma série de séries ou uma série de fotogramas ou quadros. É justamente essa série que dá condições a certo movimento e, principalmente, a determinada unidade. A história, nesse sentido, é efeito de séries de séries de acontecimentos que permitem a vivacidade de uma múltipla temporalidade em que coexiste o descontínuo dos enunciados. Em miúdos, apesar de uma série de enunciados dar a impressão de um filme (um texto coeso e imanente), o lugar de reinterpretação do arqueólogo do saber é o de restituir a singularidade de cada enunciado do arquivo como acontecimento discursivo. 
Essa postura metodológica acaba incidindo sobre duas atitudes: (1) verificamos que não se pode analisar uma série de enunciados buscando a pura continuidade que os embala, pois não existe um acontecimento original que dá existência a todos os outros; (2) como se trata de uma série de enunciados, os acontecimentos não podem ser analisados somente segundo sua singularidade, mas na relação de coexistência com outros acontecimentos. Um fazer arqueológico no nível dos saberes - descrição do acontecimento discursivo no interior do arquivo - pode buscar tentar constituir essas séries de enunciados ou séries enunciativas sem, contudo, tentar encontrar uma unidade que as inspire. Ao contrário, podemos buscar descrever as relações que as mantêm dispersas e, no entanto, regulares. A pergunta diante de um enunciado seria: o que o faz tão novo e diferente e, ao mesmo tempo, tão regular?

\section{3 ÁRVORE DE DERIVAÇÃO ENUNCIATIVA E ENUNCIADO REITOR}

A noção de enunciado para Foucault (2008) é pouco conceitual (no sentido de que permite modos de aplicação) e diz respeito a um trabalho específico com um corpus. As questões colocadas pelas descrições arqueológicas de Foucault e pelas séries enunciativas por ele estudadas garantiram um arranjo específico de descrição enunciativa. Desse quadro de descrições, a análise que Foucault oferece em A arqueologia do saber incide sobre duas noções interessantes do ponto de vista da organização dos níveis enunciativos: as noções de árvore de derivação enunciativa e de enunciado reitor. São noções que, prioritariamente, auxiliam na reflexão sobre os índices de organização de uma série enunciativa.

Essas duas noções são apresentadas por Foucault (2008) em sua discussão sobre o original e o regular. Foucault não pretendia definir, a partir delas, um centro organizador dos enunciados, de modo a delimitar um ponto de originalidade. Ao contrário, a tentativa é a de mostrar que, do mesmo modo que há acontecimentos de estatutos diferentes, também há uma estratificação do lugar dos enunciados em uma cadeia enunciativa. Isso equivale a dizer que os enunciados se diversificam uns em relação aos outros na medida em que desempenham diferentemente as regras de 
funcionamento de uma formação discursiva, concentram em si essas regras e são sintoma de funcionamento de enunciados ulteriores.

De modo que não há enunciado singular que articule todas as regras de formação de uma formação discursiva; essa maneira de conceber como estratificada a relação entre os enunciados leva Foucault a entender que existe, sim, ao menos uma árvore de derivação enunciativa a qual os enunciados integram e na qual os enunciados ocupam lugares distintos, embora haja sempre, entre eles, relações constitutivas. A metáfora da árvore diz respeito desde à força desempenhada pelas raízes e concretizada e enrijecida no tronco até os movimentos mais leves encontrados nos pequenos galhos, frágeis e delicados, e, por fim, nas folhas; sem contar, é claro, que, em se tratando de componentes de uma mesma árvore, os enunciados fazem parte de um mesmo sistema regular. Segue o que aparece em $A$ arqueologia do saber a respeito da árvore de derivação enunciativa:

[...] em sua base, os enunciados que empregam as regras de formação em sua extensão mais ampla; no alto, e depois de um certo número de ramificações, os enunciados que empregam a mesma regularidade, porém mais sutilmente articulada, mais bem delimitada e localizada em sua extensão. (FOUCAULT, 2008, p. 166).

Essa metáfora também admite certa especialização dos enunciados quando colocados em relação. Há, então, enunciados mais nucleares, que empregam as regras de formação de um modo bem mais abrangente, e enunciados derivados e especializados, que formam outros objetos aplicando as regras menos gerais, tornando-as especializadas para um determinado campo. Nas palavras de Foucault:

[...] certos grupos de enunciados empregam essas regras em sua forma mais geral e mais largamente aplicável; a partir deles, podemos ver como outros objetos, outros conceitos, outras modalidades enunciativas, ou outras escolhas estratégicas, podem ser formados a partir de regras menos gerais e cujo domínio de aplicação é mais específico. (FOUCAULT, 2008, p. 166). 
Junto a essa discussão sobre a árvore de derivação enunciativa, eis que aparece, então, uma noção de enunciado reitor, como extensão do que se entende a partir da árvore de derivação enunciativa. Os enunciados reitores são, para Foucault, aqueles que se localizam junto à raiz de uma árvore de derivação enunciativa; são os enunciados que regem o funcionamento desta última e que desempenham as regras de uma formação discursiva de modo mais concentrado e abrangente, permitindo, a partir de seu centro organizador, o surgimento de aplicações diversas no desempenho de outros enunciados. Os enunciados reitores são, segundo Foucault, os que

[...] se referem à definição das estruturas observáveis e do campo de objetos possíveis, que prescrevem as formas de descrição e os códigos perceptivos de que ele pode servir-se, os que fazem aparecerem as possibilidades mais gerais de caracterização e abrem, assim, todo um domínio de conceitos a ser construídos; enfim, os que, constituindo uma escolha estratégica, dão lugar ao maior número de opções ulteriores. (ibid., p. 166).

Na tentativa da organização de um movimento de interpretação, essa noção pode permitir organizar um corpus de pesquisa segundo o que regem as relações entre enunciados reitores na dispersão de uma cadeia enunciativa. Se, de um modo geral, a análise da função enunciativa permitirá a definição da regularidade que incide nessa função de existência dos enunciados sob uma mesma formação discursiva, o tratamento de enunciados reitores será, especificamente, o ponto que recobrirá o passo para se reconhecer a possibilidade de existência da regularidade, visto que o enunciado reitor se situa justamente na base da árvore de derivação enunciativa.

A eleição de um enunciado reitor pode ser feita a partir do reconhecimento de um acontecimento discursivo de estatuto mais importante na cadeia enunciativa. Foucault (2008) admite que há acontecimentos de níveis diferentes, uns mais importantes que os outros. Talvez o ponto de localização de enunciados reitores esteja no centro de acontecimentalização de enunciados marcantes e memoráveis 
(acontecimentalizados). Um grande evento histórico, por exemplo, pode, em hipótese, abalar os regimes discursivos e as cadeias de saberes, instituindo, nos acontecimentos discursivos, enunciados reitores que servirão de base para o desempenho de enunciados ulteriores.

$\mathrm{O}$ enunciado reitor não deve funcionar, contudo, como a origem de um determinado saber, mas como um enunciado no qual incidem mais fortemente as determinações de uma formação discursiva em relação a um objeto. Ele funciona como matriz enunciativa que delibera os domínios das regras de formação. Dessa forma, o trabalho se realiza de modo a recortar parte da árvore de derivação enunciativa e encontrar nela o desempenho de um enunciado que demarque mais insistentemente o emprego de regras de formação específicas. É a partir desse enunciado que se constitui o que chamamos de série enunciativa: a rede de enunciados que, dentre os mais diversos funcionamentos discursivos, empregam as mesmas regras de formação.

\section{DO ENUNCIADO REITOR À SÉRIE ENUNCIATIVA}

Talvez possa parecer equivocado falar, a partir de Foucault (2008), em uma pesquisa que engendre a constituição de seu corpus de análise em torno de um acontecimento discursivo. Isso porque, na verdade, todos os enunciados devem ser tratados como acontecimentos no interior do arquivo, já que cada um deles possui sua singularidade e regularidade e se inscreve em um domínio de memória, mantendo relações específicas com outros enunciados.

De qualquer forma, nada impede o pesquisador de isolar um grande acontecimento histórico como um produtor de acontecimentos discursivos bem específicos e mesmo como o eixo que engendra a existência de enunciados reitores. A grande repercussão de um acontecimento histórico pode mudar o estatuto que certos enunciados ocupam, pode deslocá-los e até mesmo apagá-los. A fim de mostrar essa sistemática, tomaremos como exemplo a eleição presidencial de 2002, que dá a Luís Inácio Lula da Silva o posto de Presidente do Brasil. 
Do ponto de vista histórico e político, a eleição de Lula em 2002 é um acontecimento marcado, midiaticamente, como uma das grandes vitórias de um candidato das massas, um candidato de origem humilde. De acordo com Sargentini, “[...] Lula, o candidato eleito, é a própria imagem do trabalhador. Ele é retratado pela mídia como exemplo de trabalhador que 'venceu'. De torneiro mecânico a presidente, ele é alçado a modelo para a sociedade" (2003, p. 132). A eleição de Lula é, sem dúvida, um desses acontecimentos que congregam certa memória e lhe garante importância histórica.

De fato, esse tipo de acontecimento não pode ser analisado como um acontecimento desprendido do resto da história, já que se presume a existência de um regime de enunciabilidade que permite o acontecimento na série. A eleição de Lula não pode, então, ser analisada como um ponto original, senão como um acontecimento que possui singularidade dentre tantos outros e que com estes mantém relações intrínsecas e extrínsecas.

Uma rápida recorrência à ciência política oferece índices de que a eleição de Lula não é única e original entre tantos outros acontecimentos. Conforme nos lembra Rodrigues, cientista político,

A massificação da vida política é um fenômeno geral nas sociedades ocidentais, que marcha com a consolidação da democracia de massas, a profissionalização da atividade de representação política, a redução do poder das classes médias e trabalhadoras, fenômenos que estamos chamando [os cientistas políticos] de "popularização da classe política' (2006, p. 33).

Em sua pesquisa, Rodrigues (2006) apresenta as mudanças ocorridas no Brasil entre as eleições de 1998 e 2002. O caso da eleição de Lula é um entre uma grade regular de candidatos de camadas populares que passaram a ocupar cadeiras em cargos políticos importantes. Não se trata, portanto, de um acontecimento original em sua irrupção, ao passo que está preso a uma trama histórica que demarca sua regularidade.

É evidente, contudo, que uma eleição presidencial é, na sociedade, um evento que recebe grande atenção, principalmente da mídia, e, por isso, se torna um acontecimento histórico. O acontecimento "eleição de Lula" 
foi, por si só, uma promessa de mudança para os brasileiros. O programa de governo era bem objetivo: distribuir renda e diminuir a pobreza, ou, em outras palavras, tornar o Brasil um país de todos, um país de igualdade social.

O slogan do Governo Federal e também a marca do Governo Federal na gestão entre 2003 e 2006 (e, mais tarde, entre 2007 e 2010) vão apostar no mote "Brasil: um país de todos". A marca do Governo Federal (reproduzida na Figura 1) procurou sintetizar a ideia de divisão igualitária de bens, de cidadania e de igualdade social (e também étnica, sexual, etc.).

Figura 1 - Marca do governo federal durante a gestão federal 2003-2006.

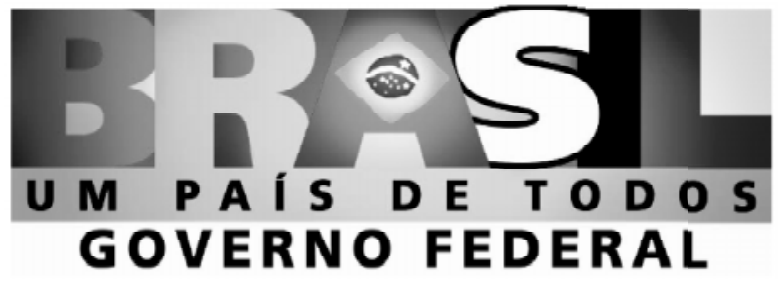

Fonte: GOVERNO FEDERAL, 2012.

Uma vez que a eleição do ex-Presidente Lula representou o avivamento da esperança de um governo destinado às massas - como mostra Sargentini (2003) -, a marca formulada para sumarizar a proposta de governo atravessa justamente o sentido da inclusão e da união, buscando impregnar a acepção de que, dentre a diversidade, é possível existir a harmonia. Esse sentido da "unidade na diferença" aparece muito marcadamente na apresentação do Manual de uso da marca do Governo Federal (GOVERNO FEDERAL, 2012). Era um texto disponível no sítio da presidência destinado à apresentação das regras de uso da marca oficial do Governo no que tange às dimensões gráficas, cores, tamanhos e possibilidades de uso. Em sua apresentação, o manual traz a seguinte explicação sobre o teor ideológico da marca:

De um lado, sincretismo, diversidade, variedade. De outro, união, afinidade, integração. Num primeiro momento, diversidade e 
integração podem parecer atributos conflitantes, mas nada espelha mais a marca do povo brasileiro do que essa rica combinação. Um povo que são vários povos, uma cultura que são muitas culturas, um país que são países sem conta. Tudo isso convivendo numa atmosfera de harmonia. Essa é a marca do Brasil: a unidade na diferença. E foi essa marca que se buscou registrar visualmente na marca oficial do Governo Federal (GOVERNO FEDERAL, 2012, p. 2).

Afirmando insistentemente a diversidade cultural brasileira, a proposta do Governo é sobre a possibilidade de dar uma identidade de união à diversidade, mostrar que toda diversidade diz respeito, acima de tudo, a um só Brasil com muitas facetas. Daí a criação de uma antonímia entre "diversidade" (e suas correlativas, "sincretismo" e "variedade") e "integração" (e suas correlativas, "união" e "afinidade"), e, para além dessa antonímia, a abertura de uma exceção para o caso específico do Brasil. Nosso país seria o lugar em que essas ideias opostas não seriam opostas, pois conviveríamos "numa atmosfera de harmonia". Um país de todos é o país da integração, que não nega as diferenças culturais, mas as inclui, como demonstra esse outro trecho do Manual:

Conceitualmente, a marca propõe uma plataforma ambiciosa e mais do que urgente: a inclusão. O Brasil da integração só se tornará um país verdadeiramente coeso quando houver uma sociedade capaz de incluir todos os seus filhos na comunhão de sua enorme riqueza. Um país de todos significa um país de oportunidades iguais, em que todos tenham acesso a direitos fundamentais e possam atender às suas necessidades básicas. O Brasil só será um país justo quando for efetivamente de todos os brasileiros. (ibid., 2012, p. 2).

Contudo, contradizendo as assertivas anteriores, esse trecho do manual define a inclusão como um programa do Governo, indicando que ela devia ser alcançada, e não que ela já existia eficazmente: o uso do futuro do indicativo em "O Brasil só será um país justo quando for efetivamente de todos os brasileiros" torna claro que o Brasil ainda não era, na época, de todos os brasileiros - ou um país integrado, unido, igualitário e cheio de afinidade. Portanto, "um país de todos", na marca e slogan do 
Governo Federal no primeiro mandato de Lula, não era uma realidade, mas um plano de ação política.

Evidentemente, essa premissa não é apresentada no slogan em si, por meio de sua sintaxe verbal. Em "Brasil, um país de todos", o sintagma nominal "um país de todos" tem função de aposto, de modo a explicitar o sentido do sintagma anterior, e, se transformado em uma hipotética oração adjetiva restritiva ou também em uma oração substantiva apositiva, o caminho segue mais para a presença de um predicado nominal construído pela utilização do presente do indicativo que pela presença do futuro do indicativo; algo como: "Brasil, que é um país de todos", ao invés de "Brasil, que será um país de todos", ou ainda "Brasil, que querem que seja um país de todos".

O slogan segue o ritmo da acontecimentalização da mudança política e instaura um efeito de ruptura e inovação dado a partir, simplesmente, da eleição do Lula Presidente: o Brasil passa a ser "um país de todos" ao mesmo tempo em que Lula assume o "cargo de maior liderança do país", em 2003. O efeito disso já é bem conhecido e discutido: é o de um espetáculo político midiatizado em uma sociedade do espetáculo.

Orlandi (2012), em uma análise muito fina e competente desse mesmo enunciado, faz uma importante discussão sobre o estatuto de "Brasil, um país de todos" nas condições de produção das relações de produção atuais. Na esteira do materialismo histórico, a autora mostra como esse enunciado se filia, ao mesmo tempo, a uma cadeia interdiscursiva própria da propaganda política e partidária de esquerda (e aos discursos de ONGs e de empresas socialmente responsáveis) e também às injunções dos discursos do neoliberalismo e da mundialização, já que, na especificação de "Brasil", o enunciado não coloca em jogo o sentido de "nação", ou de "povo", ou de "Estado". Como diz Orlandi,

Silencia-se como é do gosto da ideologia da mundialização o fato de que somos um Estado, uma Nação com suas especificidades, com seu povo, suas diferenças, como é próprio do capitalismo. Ao jeito do discurso neoliberal, mundializado, homogêneo, em que noções como democracia, cidadania não se calçam de determinações concretas. (2012, p. 126). 
Para Orlandi (2012), trata-se de um efeito de sustentação evidenciado pela relação apositiva entre "Brasil" e "um país de todos". Não há uma afirmação contra o pré-construído "O Brasil não é um país de todos”. Ao contrário, há apenas a insinuação desse pré-construído, o que faz com que o enunciado se abra ao equívoco. A autora ainda mostra que o mesmo equívoco ocorre na ambiguidade de "todos": "Somos todos nós brasileiros, que estamos aí evocados, ou todos em aberto?", questiona Orlandi (2012, p. 126). De modo geral, Orlandi quer chamar atenção para o funcionamento, nesse enunciado, da língua de vento do discurso da propaganda.

Posto numa série enunciativa, contudo, esse slogan do Governo Federal - "Brasil: um país de todos" - poderá funcionar como um enunciado reitor, pois dele é possível depreender uma força de instauração de regularidade em relação aos enunciados que se deram a partir dele. Veremos que, a partir desse mote de governo, as regras de formação desse enunciado extrapolarão o campo político e terão lugar, por exemplo, na propaganda comercial.

Do ponto de vista linguístico, o slogan do Governo até se assemelha muito a uma fórmula (KRIEG-PLANQUE, 2010). Além de ser formado por uma relação de aposto entre dois sintagmas nominais, sem a presença de verbos - o que o torna extremamente curto e memorável, há ainda certa força elocutiva na sequenciação de cinco consoantes oclusivas: "Brasil, um país de todos". É certo que "Brasil, um país de todos" não é uma fórmula, no sentido de que seja frequentemente citada e possa funcionar de forma mais ou menos autônoma em campos diferentes daquele em que foi utilizada originalmente, como prevê Krieg-Planque (2010). Contudo, vale demarcar essas características estruturais de fórmula que tornam esse enunciado, ao menos, memorável e pregnante, ainda que não constantemente reutilizável. É essa característica de memorável que o tornará retornável e reutilizável para/em outros contextos, como o de campanhas publicitárias.

Para além das características linguísticas de "Brasil, um país de todos", que condicionam a análise do enunciado como unidade para os estudos da linguagem, há de se considerar, em uma visada arqueológica, as condições de desempenho da função enunciativa que levam esse enunciado 
a exercer sua regularidade. Lembrando que, para a análise da função enunciativa, Foucault (2008) nos dá quatro direções de descrição (referencial, posição do sujeito, domínio associado e materialidade), podemos questionar o estatuto do enunciado no exercício de sua função a partir dessas quatro direções. Nesse sentido, como aparece em Foucault (2008), o enunciado deixa de ser tomado como unidade linguística, eventualmente confundida com "frase", "proposição" ou "ato de fala", e passa a ser considerado uma função em exercício: exercício de regras de formação específicas em determinado momento histórico, exercício de práticas discursivas que recortam determinadas relações entre o discurso e os saberes - no sentido de que há uma determinada vontade de verdade relacionando os saberes e o desempenho dos enunciados.

A análise do referencial não deve supor, segundo Foucault (2008), que haja uma relação estreita entre as palavras e as coisas, no sentido de assim definir algo similar à relação significante/significado, proposição/referente ou frase/sentido. Para um enunciado como a marca do Governo Federal - e veja-se que estamos tomando o enunciado nessa sua função de existência que abarca tanto sua materialidade verbal quanto imagética -, caberia questionar, então, as leis de possibilidade da própria nomeação e designação dos objetos constituídos, mas também as leis de possibilidade para tal materialização sincrética de linguagens.

No primeiro caso, poderíamos demarcar o acontecimento histórico em si, a eleição de Lula, como alavanca maior para a possibilidade de aparecimento e manutenção de tal enunciado: tratava-se, pois, de um candidato representante das massas, de um partido de esquerda, com ideias voltadas à transformação social, à distribuição de renda etc. $\mathrm{O}$ enunciado engendra a regularidade a partir de sua própria existência material: na função de acontecimento discursivo, ele projeta relações específicas entre si próprio e o objeto que recorta, visto que, nesse caso, o referencial é o próprio país (o "Brasil") e o enunciado submete o referencial às suas próprias regras de formação.

O núcleo do sintagma nominal, "Brasil", passará a ter uma singularidade em relação à regularidade a que está vinculado. É nesse sentido, e somente nesse lugar enunciativo, que o Brasil é projetado, para 
uma memória discursiva, como o país da união entre etnias e culturas diversas. Não que este seja um ponto de originalidade que fundará essa relação entre "Brasil" e os sentidos sobre a miscigenação; contudo, na condição de acontecimento discursivo, esse enunciado tanto advém de relações específicas numa determinada conjuntura quanto pode ser a base de formação de novos enunciados - dado que ele pode incidir em uma cadeia de enunciados ulteriores a ele.

É como se houvesse uma demarcação da enunciabilidade: o enunciado estabelece a regularidade na relação entre as palavras e as coisas. Por conta de determinadas condições sociais, políticas e históricas, que estão no âmbito do domínio associado em que o enunciado se inscreve, há certa vontade de verdade que prevalece e que incide sobre a existência e a manutenção do enunciável. No caso do Brasil depois da eleição de Lula, essa vontade de verdade circunda o terreno das diversas formas de inclusão social e recai sobre o desempenho das práticas discursivas e não discursivas. Essas práticas darão existência aos enunciados e a sua regularidade: o Brasil deve ser, a partir desse acontecimento discursivo, um país de igualdade, ou seja, um país de todos.

Podemos refletir também, indo além das condições históricas stricto sensu da referenciabilidade, sobre as condições históricas para que a relação enunciado/referencial se dê de tal ou tal modo no que diz respeito à materialidade verbovisual a partir da qual o enunciado se constitui. Para tanto, convém recorrermos às reflexões de Foucault (2008) sobre a materialidade do enunciado. Para Foucault, a materialidade do enunciado lhe garante certo estatuto no regular. Esse estatuto não está preso às regulações da enunciação, mas às regras de formação que definem as relações entre o enunciado e essa sua materialidade. Nesse caso, a materialidade do enunciado é um indício das suas condições de existência.

As sete cores utilizadas na composição da marca do Governo Federal demonstram esse caráter de aglomeração cultural ou de multiplicidade étnica que a marca tenta expressar. Também o traçado da bandeira do Brasil, ao centro da marca, objetiva a representação dessa miscigenação cultural: "Visualmente, a marca procura conciliar um traçado artístico sofisticado e uma moderna apresentação com a raiz primitiva do Brasil 
profundo, representada no traço rústico da bandeira no centro da composição" (GOVERNO FEDERAL, 2008, p. 2). Materialmente, encontramos a manifestação enunciativa desempenhando sua função de existência, segundo determinada vontade de verdade que produz saberes específicos sobre a relação entre Governo Federal e cidadãos brasileiros.

Em relação ao sujeito do enunciado, lembremos, primeiramente, que ele é diferente, para Foucault (2008), do autor do texto ou do sujeito que enuncia. Na verdade, Foucault (2008, p. 107) o define como "[...] um lugar determinado e vazio que pode ser efetivamente ocupado por indivíduos diferentes". A análise do sujeito no desempenho da função enunciativa exige não a verificação de alguém que a proferiu, mas a determinação da posição "[...] que pode e deve ocupar todo indivíduo para ser [...] sujeito" (2008, p. 108).

Em "Brasil, um país de todos", o sujeito do enunciado será esse lugar a ser ocupado pela manifestação da posição subjetiva: sujeito que compartilha, divide bens, distribui renda, inclui, ajuda, reconhece o diferente, vive a diferença, se responsabiliza socialmente etc. O sujeito não é um indivíduo, mas uma posição que é desempenhada pela própria existência do enunciado e pelas regras de formação que o enunciado emprega. A análise do sujeito integra o reconhecimento de relações entre vários enunciados e sistemas de enunciabilidade que definem os regimes de saber e de verdade de uma época. Se nos voltarmos ainda ao domínio das modalidades enunciativas, uma direção específica de análise da FD, poderemos averiguar a relação da posição do sujeito com os lugares institucionais que participam das práticas enunciativas.

Já que nosso objetivo nesta seção é o de realizar um percurso que vai do enunciado reitor à constituição da série enunciativa, mostraremos a análise do domínio associado somente em relação aos enunciados ulteriores ao enunciado reitor - os enunciados que surgiram mantendo relações com este último. Uma análise mais completa do domínio associado do enunciado reitor "Brasil, um país de todos" pode ser encontrada em Voss (2011). Orlandi (2012), ao discutir particularmente a língua de vento da propaganda e a rede interdiscursiva que constituem o funcionamento desse 
slogan, também oferecerá uma análise do modo como esse enunciado está preso a condições históricas de funcionamento discursivo.

Até esse ponto de nossa análise, dois passos para a constituição da série enunciativa podem ser dados como realizados: o reconhecimento de um enunciado reitor a partir de um acontecimento discursivo e a descrição da função de existência desse enunciado. O terceiro e último passo é reconhecer em outros textos traços semelhantes de desempenho da mesma função, mesmo que na formação de outros objetos do discurso.

Metodologicamente, para o analista do discurso, isso pode ser feito até mesmo rastreando-se as características de fórmula do enunciado reitor. Em nossa pesquisa, encontramos, por exemplo, textos que, verbalmente, traziam impresso o caráter cristalizado da fórmula "Brasil, um país de todos". A seguir, oferecemos algumas ocorrências desse mesmo desempenho da função enunciativa em campanhas publicitárias:

01. "Mais saúde para todos" - campanha publicitária da Monsanto (Revista Veja. Ed. N. 1834 de 24 dez. 2003. p. 103).

02. "Gol. Aqui todo mundo pode voar" - campanha publicitária da Gol Linhas Aéreas (Revista Veja. Ed. N. 1858. 16 jun. 2004. p. 6-7).

03. "Proteger a família é um direito de todos" - campanha publicitária da Bradesco Seguros (Revista Veja. Ed. N. 1859. 23 jun. 2004. p. 80-81).

Nesses três exemplos, o mote do slogan do Governo Federal foi, de certa forma, mantido. "Um país de todos" é verbalmente identificado nas três chamadas publicitárias. Contudo, não é só da relação intertextual mais ou menos direta entre textos que podemos mostrar a derivação enunciativa. Como se trata de uma questão também de derivação de objetos do discurso, o analista precisa estar atento a textos em que a função enunciativa é desempenhada muito mais nas mesmas regras de formação que nas marcas verbais explícitas, como o trabalho de Foucault (2008) indica.

Além desses casos em que havia a menção verbal ao enunciado reitor, pudemos identificar outras campanhas publicitárias em que uma mesma responsabilidade social era desempenhada pela posição de sujeito. Nesses casos, mesmo sem a relação intertextual, as regras de formação se mantêm regulares, já que o referencial e a posição do sujeito derivam do 
quadro de especificações sugeridas pelo enunciado reitor. É o caso dos excertos de campanhas publicitárias a seguir:

04. "Auto-estima: que matéria melhor uma escola poderia ensinar?" - campanha publicitária do Projeto Coca-Cola de Valorização do Jovem (Revista Época. N. 393. 28 nov. 2005. p. 83).

05. "Nós plantamos futuro" - campanha publicitária da StoraEnso (Revista Veja. N. 1834. 24 dez. 2003. p. 117).

06. "No Unibanco, cultura e educação também rendem mais" campanha publicitário do Unibanco (Revista Veja. N. 1842. 25 fev. 2004. p. 2-3).

07. "É possível produzir um monte de coisas a partir do cobre. Carteira de trabalho, por exemplo" - Campanha publicitária da Vale do Rio Doce (Revista Veja. N. 1861. 07 jul. 2004. p. 30-31).

Nesses últimos enunciados, todos chamadas de textos publicitários, podemos verificar o funcionamento das mesmas regras de formação: aquelas que dizem respeito à responsabilidade social e à cidadania. Investir no trabalho, na educação, na cultura e no "futuro" é a o modo de tornar o Brasil um país de igualdade ("um país de todos").

Evidentemente, não só em campanhas publicitárias impressas são encontradas ramificações dessa árvore cuja raiz foi o slogan do Governo Federal. De maneira mais explícita, toda a propaganda governamental esteve impregnada desse mote do governo durante todo o mandato de Lula. Nossa análise de propagandas governamentais (VOSS, 2011) mostrou isso. Mas também em programas televisivos, novelas, séries televisivas, publicidade televisionada etc. esteve presente essa injunção à responsabilidade social condensada em "Brasil: um país de todos".

\section{CONSIDERAÇÕES FINAIS}

As reflexões apresentadas neste texto tomaram como ponto de partida o slogan governamental "Brasil: um país de todos", com a finalidade de pontuar o alcance da perspectiva foucaultiana para a análise do campo associativo e das regras de formação que um enunciado reitor pode abarcar e dar visibilidade em discursos políticos e midiáticos. 
Chamamos a atenção para o efeito de acontecimento que o slogan produz, assim como para os saberes que ele agencia e faz circular em outros gêneros discursivos. Vimos que, do campo político, a ideia de "um país de todos" migra para textos da esfera publicitária, e esse domínio de memória que o slogan acaba por organizar faz dele um enunciado reitor, tal como essa noção é concebida por Foucault (2008).

A análise da posição de sujeito (um dos elementos definidores do exercício da função enunciativa) nas séries enunciativas recortadas do arquivo possibilitou-nos descrever as modalidades enunciativas do sujeito do enunciado reitor. Assim, assume esse discurso aquele sujeito que compartilha e divide bens, que distribui renda, que inclui, ajuda e reconhece o diferente, que vive a diferença e se responsabiliza socialmente.

$\mathrm{Na}$ montagem do dispositivo teórico, eleger esse slogan como enunciado reitor não procurou restabelecer o fluxo contínuo de relações de causalidade, no sentido de que foi somente a partir desse enunciado que outros foram permitidos. Na verdade, a pretensão é a de apenas situar um marco agregador de uma rede de enunciados. Dados os saberes já em jogo na cena política brasileira contemporânea, "Brasil: um país de todos" foi um condensador das regras de formação, daí podermos situá-lo na base de uma árvore de derivação enunciativa. Ele pega carona (não por acaso) com um grande acontecimento político a fim de dar ar de novidade aos mesmos anseios de uma "Nova Era".

\section{REFERÊNCIAS}

COURTINE, J-J. Discurso, história e arqueologia (Entrevista concedida a Cleudemar Alves Fernandes). In: MILANEZ, N.; GASPAR, N. R. A (des)ordem do discurso. São Paulo: Contexto, 2010. p. 17-30.

FOUCAULT, M. As palavras e as coisas: uma arqueologia das ciências humanas.

Trad. Salma Tannus Muchail. 9. ed. São Paulo: Martins Fontes, 2007.

. A arqueologia do saber. Trad. Luiz Felipe Baeta Neves. 7. ed. Rio de Janeiro: Forense Universitária, 2008.

GOVERNO FEDERAL. Manual de uso da marca do Governo Federal. Disponível em: <http://migre.me/82H1P > . Acesso em: 24 fev. 2012.

KRIEG-PLANQUE, A. A noção de fórmula em Análise do Discurso: quadro teórico e metodológico. Trad. Luciana Salazar Salgado e Sírio Possenti. São Paulo: Parábola Editorial, 2010. 
ORLANDI, E. P. Propaganda política e língua de Estado: Brasil, um país de todos. In: ORLANDI, E. P. Discurso em análise: sujeito, sentido e ideologia. Campinas, SP: Pontes, 2012. p. 107-128.

RODRIGUES, L. M. Mudanças na classe política brasileira. São Paulo: Publifolha, 2006.

SARGENTINI, V. A descontinuidade na História: a emergência dos sujeitos no arquivo. In: SARGENTINI, V.; NAVARRO-BARBOSA, p. Michel Foucault e os domínios da linguagem: discurso, poder, subjetividade. São Carlos, SP: Claraluz, 2003. p.77-96.

VOSS, J. O conceito de formação discursiva de Foucault e o tratamento de objetos da mídia: sobre a responsabilidade social na publicidade impressa brasileira. 2011. 140f. Dissertação (Mestrado em Letras) - Curso de Pós-graduação em Letras, Universidade Estadual de Maringá, Maringá, 2011.

\section{Recebido em: 18/03/12. Aprovado em: 16/03/13.}

Title: Michel Foucault's notion of governing statement and the analysis of media's discursive objects Authors: Jefferson Voss; Pedro Navarro Abstract: This paper aims at commenting on the notion of governing statement, offered by Foucault in his archeological method, and at discussing its operational possibilities in Discourse Analysis (DA). Firstly, we discuss the possibilities of analyzing discourses from the perspective of the archeological method. Following this first discussion, comes a brief passage in which we emphasize some necessary safeguards, given the specificity of some current discursive materialities. Those safeguards have to do with some of Foucault's notions: discursive formation, governing statement, tree of enunciative derivation etc. Finally, we explore Foucault's concept of governing statement and its relationship to the constitution of a research corpus. In an attempt of showing the operational function of such a notion, we analyze the role of governing statement played by the slogan "Brasil: um pais de todos". That slogan was used during the presidency of Luis Inácio Lula da Silva, from 2002 through 2006.

Key-words: Michel Foucault. Governing statement. Archeological method. Discourse Analysis. 
Título: La noción de enunciado rector de Michel Foucault y el análisis de objetos discursivos mediáticos

Autores: Jefferson Voss; Pedro Navarro

Resumen: Este texto tiene como alcance discurrir sobre la noción de enunciado rector, erigida en el interior del método arqueológico de Michel Foucault, y discutir su operacionalidad para el Análisis de Discurso (AD). Para tanto, argumentamos, primero, sobre las posibilidades de trabajo con el método arqueológico. En la secuencia, presentamos algunas advertencias que precisarian ser hechas delante de la especificidad de algunas materialidades discursivas contemporáneas. Esas advertencias dicen al respecto de algunas nociones arqueológicas de Foucault: formación discursiva, enunciado rector, árbol de derivación enunciativa etc. Finalmente, exploramos la noción de enunciado rector de Foucault y su relación con la constitución del corpus de una investigación. En el intento de mostrar la operacionalidad de tal noción, analizaremos el papel de enunciado rector desempeñado por el slogan del Gobierno del exPresidente Luís Inácio Lula da Silva en la gestión presidencial de 2002 a 2006, "Brasil: un país de todos".

Palabras-clave: Michel Foucault. Enunciado Rector. Método Arqueológico. Análisis del Discurso. 